\title{
Evaluation of Swede score and Reid score to improve the predictive value of colposcopy and its correlation with histology
}

\author{
Urmila Karya, Azme Zehra*, Anupam Rani
}

Department of Obstetrics and Gynecology, LLRM Medical College, Meerut, Uttar Pradesh, India

Received: 28 February 2020

Accepted: 30 March 2020

\section{*Correspondence:}

Dr. Azme Zehra,

E-mail: azmezehra88@gmail.com

Copyright: (C) the author(s), publisher and licensee Medip Academy. This is an open-access article distributed under the terms of the Creative Commons Attribution Non-Commercial License, which permits unrestricted non-commercial use, distribution, and reproduction in any medium, provided the original work is properly cited.

\begin{abstract}
Background: Cervical carcinoma is the second most common malignancy amongst women in India. It is regarded as a public health problem and a priority in cancer control programmes by the WHO. Colposcopy has proven to be very useful in identifying and guiding the biopsy of dysplastic lesion. To minimize inter-observer variation, colposcopic scoring system has been introduced.

Methods: A prospective cross- sectional study including 250 women in whom the prevalence of different grades CIN was done. Co-relation of Pap (cytology) with colposcopy scoring system viz. Reid's and Swede scores, has been made in this study. The two screening methods were compared and their statistical association with histological findings were analyzed.

Results: Per speculum examination performed in 250 sexually active women with suspicious looking cervix, belonging to 25-60 years of age, with most common presenting complaints of pain abdomen (38.8\%) followed by leucorrhoea, irregular cycles and Post coital bleed. Unhealthy cervix (49.2\%) and persistent discharge (28\%) were the most common indications for colposcopy. An assessment of both SWEDE score and Reid score as a function of histological findings was done, while Swede score of $>5$ showed slightly more sensitivity (100\%) for diagnosing CIN1+ lesions, Reids score of $>5$ was more specific (100\%) with a higher positive predictive value (100\%) for diagnosing CIN 1, 2, 3 and invasive cervical carcinoma. There was a marked positive association between Reid score and SWEDE score.

Conclusions: The colposcopic scoring systems and histopathology showed significant compliance. Predictive accuracy of colposcopy increased with increasing severity of disease.
\end{abstract}

Keywords: Cervical intraepithelial lesion, Reid's colposcopic index, Swede score

\section{INTRODUCTION}

Carcinoma cervix is an important cause of female mortality in our country. India alone accounts for one quarter of worldwide burden. It is estimated that cervical cancer occurs in approx. 1 in 53 Indian women during their lifetime as compared to 1 in 100 women in developed world and India brunt's $18 \%$ of the invasive cancer cervix in world. ${ }^{1}$ Cervical intraepithelial neoplasia (CIN) or cervical dysplasia is a premalignant condition of the cervix caused by the human papilloma virus (HPV).
Albeit, it is most commonly encountered STI with unavoidable massive prevalence worldwide but easy accessibility of the cervix to clinical examination, application of cytology and tissue sampling procedure have led to extensive screening programme for early detection and treatment of the disease as invasive cancer.

The squamo-columnar junction represents the transformation zone and Atypical metaplasia with abnormal nuclear changes mark the precursor for dysplasia and malignancy. 
PAP is still the most commonly recommended screening test, but numerous studies demonstrate, that sensitivity of a single Pap smear for high-grade CIN2+ or worse lesions is low and cytology-based screening methods are difficult to implement is a low-cost resource setting due to laboratory and skilled technical expertise involved. Hence, presently, visual inspection with acetic acid (VIA) or visual inspection with Lugol's iodine (VILI) is being recommended as the preferred test for universal screening in developing countries. VIA is inexpensive, its results are immediately available but its accuracy and reproducibility is questionable because of lack of standardization. Nevertheless, validation of all the screening procedures, colposcopy remains the reference standard being a simple, non-invasive OPD procedure, it helps in determining the location, size and extent of abnormal cervical lesions. And to minimize the inter observer variation, colposcopic scoring systems like Reid's colposcopic index (RCI) and Swede scores have been employed. ${ }^{2}$

The purpose of this study was to evaluate the diagnostic efficacy of colposcopy using RCI and Swede score and to determine the degree of correlation between the two indices and histopathologic evidence, for the ultimate goal of improving effectiveness of secondary cervical cancer prevention.

\section{METHODS}

A prospective cross- sectional study was conducted in the department of obstetrics and gynecology, in collaboration with department of pathology LLRM Medical College and associated with SVBP Hospital, Meerut from June 2018 to May 2019 comprising 250 women who fulfilled the selection criteria attending gynae OPD. Ethical clearance was obtained from the Institution's ethics committee.

\section{Inclusion criteria}

- Women of aged between 21-65 years, sexually active, suspicious looking cervix post coital bleeding, persistent inflammatory smears, persistent leucorrhoea not responding to antibiotics, VIA /VILI positive, Pap smears showing atypia.

\section{Exclusion criteria}

- Obvious growth/ frank lesion on cervix, pregnant/nulliparous women, severe debilitating disease, history of pelvic irradiation, women with clinical evidence of acute pelvic infection, previous procedure on cervix like excision biopsy, cryotherapy and conization, unsatisfactory colposcopy or known case of CA cervix.

Detailed clinical history taken, general physical and local examination with Cusco's speculum was performed all included cases and was recorded in a proforma. A naked eye examination of cervix and a pap smear was followed by colposcopy. Saline test was performed to study the vasculature of cervix. Visual examination with acetic acid and Lugol's iodine was done for any obvious lesions or distorted margins and surface integrity of cervix, which were then graded. Scoring of all the findings as per RCI and Swede score was done. Lastly, for Swede score, size of the lesion was determined and colposcopy directed biopsies were taken from abnormal areas. Colposcopic and histopathology findings were compared and reported. Women with CIN2/3 were advised treatment, according to the standard of care.

\section{Statistical analysis}

Statistical analysis of all the recorded data was done on MS excel and SPSS 26 version 64-bit software.

\section{RESULTS}

\section{Socio-demographics}

Regarding age distribution, high incidence of CIN was noted in age group of 24-65 years, with the mean of 41.64 years of age. Maximum women belonged to age group 31-40 years (41.6\%) followed by 41-50 years (27.6\%). Amongst rural or urban showed slight rural preponderance $(53.2 \%$ versus $46.8 \%)$. Most women had a parity between 1 to $4(221,88.4 \%)$ followed by 5 or more $(27,10.8 \%)$. Two nulliparous women $(0.8 \%)$ were also included in the study. Additionally, it was found that most women belonged to low $(121,48.4 \%)$ or middle $(125,50 \%)$ socioeconomic status. Women were mostly Hindus $(157,62.8 \%)$ followed by Muslims $(65,26 \%), 18$ (7.2\%) Sikh and 10 (4\%) Christian females. Most Women married between 18 to 25 years $(237,94.80 \%)$. However, 5 women $(2.0 \%)$ married before 18 years of age were also documented. Most of the women in the study were using one or the other form of contraceptives $(162,64.8 \%)$ while $88(88,35.2 \%)$ were not using any. Barrier devices were the most common form of contraceptive $(76,30.4 \%)$ used in the study followed by oral contraceptive pills $(35,14 \%) .19(7.6 \%)$ women had a positive history of tobacco use in the past.

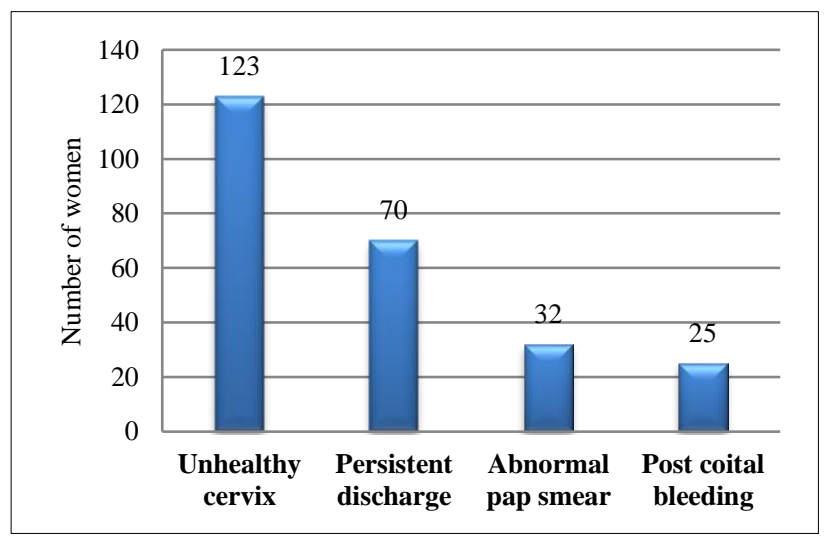

Figure 1: Indications for colposcopy. 


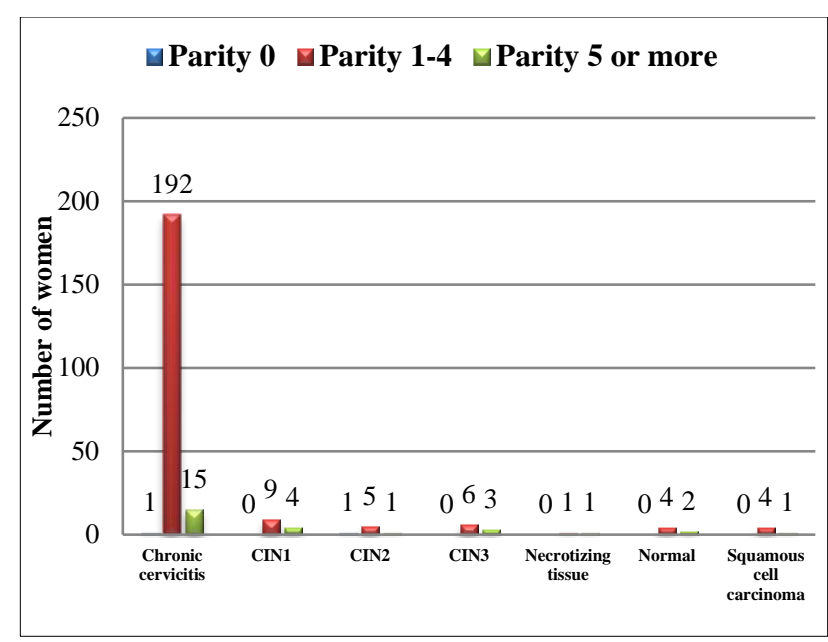

Figure 2: Histopathology and parity status.

\section{Indications for colposcopy}

In the present study, subjects referred for colposcopy on the basis of an abnormal per speculum findings i.e. cervical erosion (37.6\%), vaginal discharge (14\%), hypertrophied cervix $(29 \%)$, multiple nabothian follicles
(14\%) and (12.8\%) abnormal Pap smear (Figure 1). Since, Pap smear was taken for all cases, and cytology findings graded the study population into NILM in $214(85.6 \%)$, ASCUS in $15(6 \%)$, LSIL in $8(4 \%)$, HSIL in $10(4 \%)$, persistent inflammatory changes in $1(0.4 \%)$ respectively (Figure 1).

\section{Histopathology findings}

In the present study, prevalence of CIN of any grade was detected in $29(11.6 \%)$ cases. With CIN 1 in $13(5.2 \%)$ and CIN2 in $7(2.8 \%)$ and CIN3 in $9(3.6 \%)$ cases were seen. Upon corelating, histopathology findings with age, majority were women $>40$ years of age $(p=0.0373)$ with CIN3 lesions, in comparison to the ones belonging to $<40$ years age. Additionally, it was observed that in age group of 31-40 years, 41-50 years and 51-60 years had CIN+ lesion were $10(4 \%), 11(4.4 \%)$ and $7(2.8 \%)$ in women respectively (Table 1). The prevalence of CIN1,2,3 and Invasive cervical cancer in women with parity 1 to 4 was $10.8 \%$ (24/221 women). The prevalence increased to $33.33 \%$ (9/27 women) in women with parity 5 or more. This increase in the prevalence with higher parity was statistically significant $(\mathrm{p}=0.0011)$ (Figure 2) (Table 1).

Table 1: Histopathology and age groups.

\begin{tabular}{|lllllll|}
\hline Histopathology & $\mathbf{2 1 - 3 0}$ years & $\mathbf{3 1 - 4 0}$ years & $\mathbf{4 1 - 5 0}$ years & $\mathbf{5 1 - 6 0}$ years & $\mathbf{7 0 0}$ years & Total \\
\hline Chronic cervicitis & 33 & 90 & $\mathbf{5 6}$ & $\mathbf{2 6}$ & 3 & $\mathbf{2 0 8}$ \\
\hline CIN1 & 1 & 4 & 7 & 1 & 0 & 13 \\
\hline CIN2 & 0 & 4 & 2 & & 1 & 7 \\
\hline CIN3 & 0 & 2 & 2 & 4 & 1 & 9 \\
\hline Necrotizing tissue & 0 & 1 & 0 & 1 & 0 & 2 \\
\hline Normal & 1 & 3 & 1 & 1 & 0 & 6 \\
\hline Invasive cervical cancer & 1 & 0 & 1 & 2 & 1 & 5 \\
\hline Total & 36 & 104 & 69 & 35 & 6 & 250 \\
\hline
\end{tabular}

Table 2: Diagnostic efficiency testing of Swede score (more than 5) with respect to histopathology.

\begin{tabular}{|c|c|c|}
\hline & Histopathology positive (CIN1+) & $\begin{array}{l}\text { Histopathology negative (normal/C. } \\
\text { cervicitis) }\end{array}$ \\
\hline Positive (5 or more) & 30 & 10 \\
\hline Negative (less than 5) & 4 & 204 \\
\hline \multicolumn{3}{|l|}{ p value and statistical significance } \\
\hline Test & Fisher's exact test & \\
\hline $\mathrm{p}$ value & $<0.0001$ & \\
\hline p value summary & $* * * *$ & \\
\hline One- or two-sided & Two-sided & \\
\hline Statistically significant $(\mathrm{p}<0.05)$ ? & Yes & \\
\hline Effect size & Value & 95\% CI \\
\hline Sensitivity & 0.8824 & 0.7338 to 0.9533 \\
\hline Specificity & 0.9533 & 0.9161 to 0.9744 \\
\hline Positive predictive value & 0.7500 & 0.5981 to 0.8581 \\
\hline Negative predictive value & 0.9808 & 0.9516 to 0.9925 \\
\hline
\end{tabular}




\section{Colposcopy indices}

\section{Swede score}

An assessment of the colposcopy Swede score for the 250 women highlighted that most of the women had a score of $2(31.6 \%), 3(28 \%)$ and $4(14 \%) .7 .2 \%$ women had Swede score of 8 or more which is highly suggestive of high grade/suspected invasive cancer (CIN 2+) and 16\% women had a score of 5 or more, suggestive of noninvasive high-grade cancer (CIN 2+). An Assessment of Swede score more than 5 with respect to histopathology for diagnosis of CIN2+ lesions were done. It was seen that SWEDE score of 5 or more has a very high sensitivity $(100 \%)$, specificity $(91.63 \% \%)$ along with negative predictive value $(100 \%)$ for the diagnosis of such lesions. However, the positive predictive value for the same is very less at $52.50 \%$. This highlights the utility of Swede index of 5 or more than 5 as a tool for noninvasive diagnosis of CIN2+ lesions is slightly limited because of the poor PPV especially due to its inability to correctly differentiate CIN2 from CIN1 lesions but as the SWEDE score increased the histology progressively worsened from chronic cervicitis to invasive cervical cancer ( $\mathrm{p}$ value $<0.0001$ ) (Table 2 and 3 ).

Table 3: Swede colposcopy index at cut off of 5 or higher for detection of CIN2+ lesions.

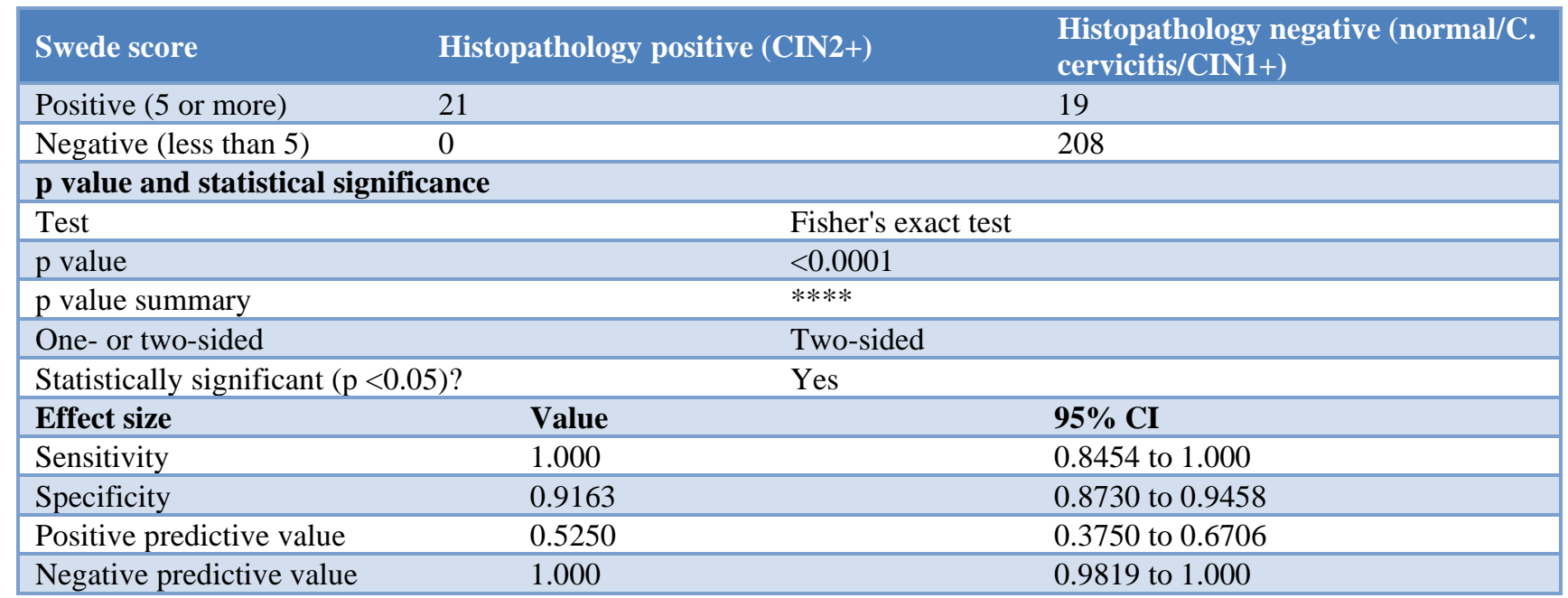

Table 4: Diagnostic efficiency testing of Reid score (more than 5) with respect to histopathology.

\begin{tabular}{|c|c|c|c|}
\hline & \multicolumn{2}{|c|}{ Histopathology positive (CIN1+) } & $\begin{array}{l}\text { Histopathology negative } \\
\text { (normal/C. cervicitis) }\end{array}$ \\
\hline Positive ( 5 or more) & \multicolumn{2}{|c|}{23} & 0 \\
\hline Negative (less than 5) & \multicolumn{2}{|c|}{11} & 214 \\
\hline \multicolumn{4}{|c|}{ p value and statistical significance } \\
\hline \multicolumn{3}{|c|}{ Test } & Fisher's exact test \\
\hline \multicolumn{3}{|l|}{$\mathrm{p}$ value } & $<0.0001$ \\
\hline \multicolumn{3}{|l|}{ p value summary } & $* * * *$ \\
\hline \multicolumn{3}{|l|}{ One- or two-sided } & Two-sided \\
\hline \multicolumn{3}{|c|}{ Statistically significant $(\mathrm{p}<0.05)$} & Yes \\
\hline \multicolumn{2}{|c|}{ Effect size } & Value & $95 \% \mathrm{CI}$ \\
\hline \multicolumn{2}{|l|}{ Sensitivity } & 0.6765 & 0.5084 to 0.8087 \\
\hline \multicolumn{2}{|l|}{ Specificity } & 1.000 & 0.9824 to 1.000 \\
\hline \multicolumn{2}{|l|}{ Positive predictive value } & 1.000 & 0.8569 to 1.000 \\
\hline \multicolumn{2}{|l|}{ Negative predictive value } & 0.9511 & 0.9146 to 0.9725 \\
\hline
\end{tabular}

*-Excluding 2 cases of necrotizing tissue.

\section{$R C I$}

Another variable such as, Reid's Index for colposcopy evaluation of the women showed that most women had a score of $1(26.8 \%), 2(43.2 \%)$ and $3(11.6 \%) .9 .2 \%$ women in the study population, had a Reids score of 5 or more, Furthermore, this assessment of Reid score more than 5 with respect to histopathology for diagnosis of CIN2+ lesions shows a very high sensitivity (95.24\%), specificity $(98.68 \%)$ and Positive Predictive value $(86.96 \%)$ along with negative predictive value $(99.56 \%)$ 
for the diagnosis of such lesions. This highlights the utility of Reids index of 5 or more than 5 as a useful tool for non-invasive diagnosis of CIN2+ lesions and it was observed that as the Reids score increased the histology progressively worsened from chronic cervicitis to Invasive cervical cancer ( $\mathrm{p}$ value $<0.0001$ ) (Table 4 and $5)$.

Table 5: Diagnostic efficacy of Reids colposcopy index at cut off of 5 or higher for detection of CIN2+ lesions.

\begin{tabular}{|c|c|c|c|}
\hline \multicolumn{3}{|c|}{ Histopathology positive (CIN2+) } & $\begin{array}{l}\text { Histopathology negative (normal/C. } \\
\text { cervicitis/CIN1+) }\end{array}$ \\
\hline Positive ( 5 or more) & \multicolumn{2}{|l|}{20} & 3 \\
\hline Negative (Less than 5) & \multicolumn{2}{|l|}{1} & 224 \\
\hline \multicolumn{4}{|c|}{$p$ value and statistical significance } \\
\hline \multicolumn{2}{|c|}{ Test } & \multicolumn{2}{|l|}{ Fisher's exact test } \\
\hline \multicolumn{2}{|l|}{$\mathrm{p}$ value } & \multicolumn{2}{|l|}{$<0.0001$} \\
\hline \multicolumn{2}{|l|}{$\mathrm{p}$ value summary } & \multicolumn{2}{|l|}{$* * * *$} \\
\hline \multicolumn{2}{|c|}{ One- or two-sided } & \multicolumn{2}{|l|}{ Two-sided } \\
\hline \multicolumn{2}{|c|}{ Statistically significant $(\mathrm{p}<0.05) ?$} & \multicolumn{2}{|l|}{ Yes } \\
\hline \multicolumn{2}{|c|}{ Effect size } & & $95 \% \mathrm{CI}$ \\
\hline \multicolumn{2}{|l|}{ Sensitivity } & & 0.7733 to 0.9976 \\
\hline \multicolumn{2}{|l|}{ Specificity } & & 0.9619 to 0.9964 \\
\hline \multicolumn{2}{|l|}{ Positive predictive value } & & 0.6787 to 0.9546 \\
\hline Negative predictive value & 0.9956 & & 0.9753 to 0.9998 \\
\hline
\end{tabular}

Table 6: Comparison of the various diagnostic efficiency parameters for various modalities combined.

\begin{tabular}{|llll|}
\hline Effect & Colposcopy versus histology & Pap versus histology & Pap versus colposcopy \\
\hline Sensitivity & 0.6765 & 0.8235 & 0.7826 \\
\hline Specificity & 1.000 & 0.9717 & 0.9289 \\
\hline Positive predictive value & 1.000 & 0.8235 & 0.5294 \\
\hline Negative predictive value & 0.9511 & 0.9717 & 0.9766 \\
\hline Likelihood ratio & & 29.10 & 11.01 \\
\hline p value & $<0.0001$ (significant) & $<0.0001$ (significant) & $<0.0001$ (significant) \\
\hline
\end{tabular}

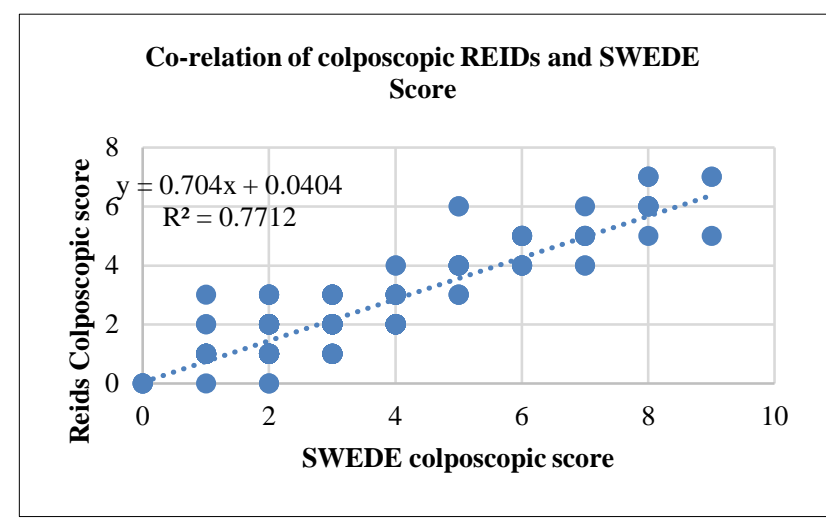

Figure 3: Co-relation of colposcopic REIDs and SWEDE score

\section{Association between the colposcopy indices}

As we co-relate the Reid's score and Swede Score-They were found to be positively associated. The Pearson coefficient $\mathrm{R}$ for the 2 linear ordinal variables was 0.8788 and $\mathrm{r}$ square value was 0.7712 . This value highlights that
$77 \%$ variability in the Reid score can be attributed to changes in the Swede score alone and vice versa, which was statistically significant ( $\mathrm{p}<0.001)$ (Figure 3 ).

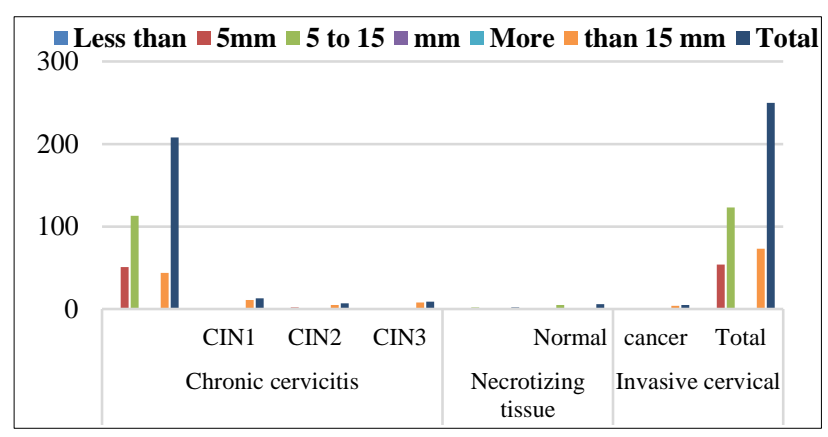

Figure 4: Lesion size and histology.

\section{Lesion size}

Interestingly, Lesion size can be used as a predictor of high-grade lesion as it was observed that women with lesions more than $15 \mathrm{~mm}$ in size or involving 3-4 
quadrants were CIN2 $(7,2.8 \%)$ and CIN3(9,3.6\%) with 5 invasive cervical cancer cases (Figure 4).

Table 7: Socoi demographic factors comparison.

\begin{tabular}{|c|c|}
\hline Study & Major finding \\
\hline \multicolumn{2}{|l|}{ Age (in years) } \\
\hline Ramadevi et al & More in females $>30$ years \\
\hline Vaidya et al & More in $>35$ years \\
\hline Shalini et al & Most common in $>35$ years \\
\hline Verma I et al & $\begin{array}{l}\text { Most women in } 31-50 \text { years age } \\
\text { group }(71.20 \%)\end{array}$ \\
\hline Ale OV et al & Most women in age group 40-49 \\
\hline Present study & $\begin{array}{l}\text { Most women in } 31-50 \text { years age } \\
\text { group }(69.20 \%)\end{array}$ \\
\hline \multicolumn{2}{|l|}{ Parity } \\
\hline $\begin{array}{l}\text { Kushtagi and } \\
\text { Fernandez }\end{array}$ & More in parity $>2$ \\
\hline Vaidya et al & More in parity $>4$ \\
\hline Ale OV et al & More in parity $1-4$ \\
\hline Ramadevi E et al & Most among parity $1-4$ \\
\hline Present study & $\begin{array}{l}\text { Significant increase in prevalence } \\
\text { from parity } 1-4(10.8 \%) \text { to parity } 5 \\
(33.34 \%)\end{array}$ \\
\hline \multicolumn{2}{|c|}{ Socioeconomic status } \\
\hline Vaidya et al & $\begin{array}{l}\text { Low socioeconomic status has } \\
\text { important role }\end{array}$ \\
\hline Indu verma et al & Middle - 53.60, upper-26 \\
\hline Present study & Middle - $50 \%$, upper- $1.6 \%$ \\
\hline \multicolumn{2}{|l|}{ Smoking status } \\
\hline Slattery ML et al & Non-smokers at more risk \\
\hline Present study & Non-smokers $-54.8 \%$ \\
\hline \multicolumn{2}{|l|}{ Religion } \\
\hline Verma I et al & $\begin{array}{l}\text { Hindu females (48.80) and Sikh } \\
(48.80) \text { females most common }\end{array}$ \\
\hline Present study & Hindu $(62.7 \%)$ most common \\
\hline \multicolumn{2}{|c|}{ Contraceptive use } \\
\hline Ashmita D et al & $\begin{array}{l}\text { IUCD }(32.7 \%) \text { and OCP }(11.5 \%) \\
\text { were most common }\end{array}$ \\
\hline Verma I et al & $\begin{array}{l}\text { Barrier method (25.60) and tubal } \\
\text { ligation }(20.80 \%) \\
\text { most common }\end{array}$ \\
\hline Present study & $\begin{array}{l}\text { Barrier }(30.4 \%) \text { and OCP (14\%) } \\
\text { most common }\end{array}$ \\
\hline \multicolumn{2}{|c|}{ Place of residence } \\
\hline Verma I et al & Urban $(63.20 \%)$ most common \\
\hline Present study & Rural (53.2\%) most common \\
\hline
\end{tabular}

\section{Pap (cytology), colposcopy and histopathology}

Literature is replete with data pertaining to the sensitivity of pap smear and colposcopy ranging from $27 \%$ to $50 \%$ versus $44 \%$ to $89 \%$ respectively. Specificity of Pap smear and colposcopy ranging from $19.5 \%$ to $88.7 \%$ versus 52 93.4\% respectively. On comparing the PAP smear and Histology and colposcopic findings, it was found that PAP smear, as a diagnostic tool for cervical screening had good sensitivity and specificity, with variable positive predictive value and diagnostic accuracy. This was attributed to the high number of false negative smears (Table 6).

\section{DISCUSSION}

\section{Sociodemographic factor comparison}

Ramadevi E et al in their study showed the prevalence of CIN was higher in women over 30 years. $^{3}$ Vaidya A, showed in his study that CIN was more prevalent in the age group of $>35$ years Shalini et al showed the mean age with cancer cervix was 35 versus 32 in women with benign pathology in cervix.+ Kushtagi and Fernandez showed the prevalence of CIN significantly higher in parity of more than 2. Vaidya et al showed more positive cases of CIN were found with parity more than. ${ }^{4}$ Ale OV et al in their study saw most common age group affected was between 40-49 years with most commonly parity between 1-4. ${ }^{6}$ Which can attribute to hormonal and nutritional changes or OCP use. Devi R et al, showed the incidence of CIN was higher among low income group (19.5\%). Socio economic status had always been playing an epidemiological role in genesis of dysplasia. Vaidya et al had also showed that low socio-economic status had a definite role on the development of dyskaryosis. In this study $80 \%$ of CIN I and $50 \%$ of CIN II were of lowincome group (Table 7). ${ }^{4}$

Poor personal hygiene poor living conditions, unstable marriages and early age at first intercourse are factors associated with both low socio-economic conditions and cervical cancer. Slattery ML et al found out that the odds of women developing cervical cancer was greater in women who were non-smokers than in women who smoked. ${ }^{7}$ Pregnancy associations appear to relate to the number of live births rather than to miscarriages or abortions, multi-parity is most pronounced among premenopausal women and oral contraceptive users. Although this study does show a strong relation with parity, Human papillomaviruses types 16 and 18, is significantly associated with number of births and explain the strong relation of parity to risk. This study results indicate the need for further consideration of reproductive factors on cervical cancer risk, with attention given to possible mechanisms of action, including hormonal factors and cervical trauma. ${ }^{8}$

\section{Indications of colposcopy}

In reference to the study of Chhabra et $\mathrm{al}^{9}$ where more than two third of the women were in the reproductive age group. It also collaborates the fact that sexually active women in the reproductive age group have a higher chance of having an unhealthy cervix. In a study conducted by Bukhari $\mathrm{MH}$ et al peak incidence of abnormal smears were found during age group of 30-39 years. ${ }^{10}$ The sociodemographic parameters and patient profile of this study were very similar to study by 
Kärrberg et al, in which had included pregnant women also but found similar results. ${ }^{11}$ In a study from Belgaum by Durdi et al, discharge per vaginum and postcoital bleeding were the predominant complaints which was same in the present study. ${ }^{12}$ A study by Ranga $\mathrm{R}$ et al state main indication for colposcopy as abnormal pap smear (79\%), persistent discharge, postcoital bleeding and unhealthy cervix were other indication in $9.3 \%, 4.1 \%$ and $11 \%$ respectively. ${ }^{13}$ Ale OV et al in contrast to what we found, stated main indication of colposcopy was abnormal Pap smear in $48 \%$ cases. ${ }^{6}$ But, similar abnormal Pap smear referrals $(9.1 \%)$ were seen in a study done by Penumali S et al. ${ }^{14}$

Table 8: Comparison of Swede score related parameters with findings of other studies.

\begin{tabular}{|llllll|}
\hline Study & Score & Sensitivity & Specificity & PPV & NPV \\
\hline Swede score & & & & & \\
\hline Strander et al & $\geq 5$ & $79 \%$ & $95 \%$ & $80 \%$ & $16.3 \%$ \\
\hline Nessa et al & $\geq 5$ & $83 \%$ & $24.2 \%$ & $82.60 \%$ & $100 \%$ \\
\hline Kuswah et al & $\geq 5$ & $100 \%$ & $91.30 \%$ & $75 \%$ & $98.08 \%$ \\
\hline Present study & $\geq 5$ (CIN1+) & $88.2 \%$ & $95.33 \%$ & $52.50 \%$ & $100 \%$ \\
\hline & $\geq 5$ (CIN2+) & $100 \%$ & $91.63 \%$ & \\
\hline
\end{tabular}

Table 9: Comparison of Reid score related parameters with findings of other studies.

\begin{tabular}{|llll|l|}
\hline Study & Sensitivity & Specificity & PPV & NPV \\
\hline Reid score & & & & \\
\hline Mousavi et al & $74 \%$ & $90.7 \%$ & $92 \%$ & $70.5 \%$ \\
\hline Durd et al & $85.2 \%$ & $99.6 \%$ & $95.8 \%$ & $98.3 \%$ \\
\hline Hong et al & $91.3 \%$ & $92.9 \%$ & $93.6 \%$ & $90.3 \%$ \\
\hline Pimple et al & $74.5 \%$ & $92.2 \%$ & $42.9 \%$ & $96 \%$ \\
\hline Kuswah et al & $94.44 \%$ & $91.48 \%$ & $80.95 \%$ & $97.73 \%$ \\
\hline Singla et al & $78.3 \%$ & $90.5 \%$ & & \\
\hline Present study & & & & \\
\hline$\geq 5($ CIN1+) & $67.65 \%$ & $100 \%$ & $100 \%$ & $95.11 \%$ \\
\hline$\geq 5($ CIN2+) & $95.24 \%$ & $98.68 \%$ & $86.96 \%$ & $99.56 \%$ \\
\hline
\end{tabular}

Table 10: Comparison of lesion size and histopathology.

\begin{tabular}{|lllllll|}
\hline Study & Chronic cervicitis (\%) & CIN1 (\%) & CIN2 (\%) & CIN3(\%) & SCC (\%) & Total (\%) \\
\hline Kuswah et al & $24(36.9 \%)$ & $22(33.8 \%)$ & $6(9.2 \%)$ & $10(15.4 \%)$ & $3(4.6 \%)$ & $65(100 \%)$ \\
\hline Ranga R et al & $44(37 \%)$ & $42(35.3 \%)$ & $7(5.9 \%)$ & $21(17.6 \%)$ & $5(4.2 \%)$ & $119(100 \%)$ \\
\hline Present study & $214(86.29 \%)$ & $13(5.2 \%)$ & $7(2.8 \%)$ & $9(3.62 \%)$ & $5(2.01 \%)$ & $248(100 \%)$ \\
\hline
\end{tabular}

\section{Histology with age and parity}

Penumali $\mathrm{S}$ et al, who did a study on 220 women and also found $52(26.64 \%)$ and $24(10.9 \%)$ were diagnosed as CIN 1 and CIN2,3. Abdel-Haldi $M$ et al in their study found CIN 1 in $0.08 \%$ cases and CIN2,3 in $0.03 \%$ cases. ${ }^{15}$ Basu $\mathrm{P}$, et al in a study found $611(2.9 \%)$ cases in CIN1, $130(0.6 \%)$ cases in CIN2,3. ${ }^{16}$

Similarly, in a study by Ashmita D et al high incidence of CIN was found among the age group 30-49 years with mean age 41 years which was seen in $19 \%$ of cases. ${ }^{17}$ Kushtagi and fernands et al in their study showed the prevalence of CIN was higher in women over 30 years. ${ }^{3}$ Vaidya A et al showed in his study of $>35$ years. Shalini et al showed the mean age of patients with cancer cervix was 35 versus 32 in patients with being pathology in cervix. ${ }^{4}$ In study of Ashmita D et al, increased incidence of CIN among multiparous women. 20.55 were para 2, $15.7 \%$ were para 3 and $15 \%$ were para 4 or more. ${ }^{17}$ Similar study by Shalini et al showed the mean parity was 4.2 , in patients with invasive cancer. ${ }^{5}$

Kushtagi and fernands showed the prevalence of CIN was significantly higher in parity of more than $2 .{ }^{3}$ Vaidya et al showed more positive cases of CIN were found with parity more than 4 . This might be attributed to hormonal and nutritional changes, OCP uses, almost $11 \%$ showed features of CIN. ${ }^{4}$

\section{Swede and RCI}

The utility of Swede score as a useful marker for predicting the severity of the cervical lesion has also been 
demonstrated by Strander et al and Bowring et al, who found that a score of 8 or higher had a specificity of $95 \%$ for CIN2 or worse with a sensitivity of $38 \%$, whereas lowering the cutoff to 6 improved the sensitivity at the expense of specificity. ${ }^{18,19}$ Lower scores showed high negative predictive values; a score of 3 or less resulted in a negative predictive value of $90 \%$. Like Swede score, this highlights the utility of Reids score also as a useful marker as a predictor of severity of the cervical lesion. Singla et al also found similar results with Reids score cutoff as $4 .^{20}$ Sensitivity and specificity were $78.3 \%$ and $90.5 \%$ to detect low grade lesions, respectively, and for detecting high grade lesions, sensitivity improved to $92.9 \%$ and specificity was $86.5 \%$ (Table 8 and 9). An assessment of the coefficient of variability $(\mathrm{R} 2=0.7753)$ explained that changes in Swede score explained $77 \%$ of the variability in the Reids score similar findings were observed in the studies conducted by Ranga $\mathrm{R}$ et al and kushwah S. ${ }^{13,21}$ Ranga R et al, demonstrated correlation coefficient (R2) of 0.919 between Swede score and Reid score.

\section{Lesion size}

Kierkegaard et al, showed in their study that lesion size larger than $50 \%$ ( 2 or more quadrants) of the visible cervix had an odds ratio of 3.6 (95\% confidence interval: 2.1-6.3). ${ }^{22}$ This results correlate well with the studies done by Kushwaha et al and Ranga R et al, Kushwaha S and Kushwaha $\mathrm{B}$ showed that significant association between lesion size and CIN + lesion $(\mathrm{p}<0.05)$. Lesion size $>15 \mathrm{~mm}$ involving $>3$ quadrants was present in 14 subjects. On histopathology, CIN II + lesions were seen in 19 subjects, out of whom 8 had lesion of size $\geq 15 \mathrm{~mm}$. Hence lesion size parameter included in swede score act as a good predictor of high-grade lesions (Table 10). ${ }^{21,22}$

\section{Pap cytology, colposcopy and histopathology}

Data suggest that with colposcopy as a screening tool, the rate of false negative cytology could be significantly reduced. Colposcopy enhances cervical screening particularly in women with otherwise negative smears. Correlation between cytology and HPE is poor as far as mild dysplasias were concerned. But the correlation becomes surprisingly good for moderate and severe dysplastic lesions. This indicates the usefulness of colposcopy in diagnosing lesions missed by Pap smear as was seen in a meta- analysis by Olaniyan et al. ${ }^{3}$ Most of the women in this study reported no significant finding on the cytology $(214,85.6 \%)$. Spectrum of findings on Pap smear varied from low risk lesions like Persistent inflammatory changes $(1,0.4 \%)$ and LSIL $(8,3.2 \%)$ to high risk lesions like HSIL (10,4\%).

Although studies show, Pap test to be equally sensitive to histopathological examination for the early detection of different cervical lesions. However, it is advised to perform biopsy if any abnormalities are detected in Pap smear for correlation and confirmation. Carcinoma cervix is one of the most common cancers in women and it is the most researched disease. The regular screening of population by Pap smear is a cost-effective method for early detection of premalignant and malignant cervical lesions. Correlation of cervical cytology with cervical biopsies has been a common component of continuous quality improvement programme for accreditation purposes. ${ }^{22}$ Ashmita D et al in her study showed, pap smear had better specificity $(83.3 \%$ versus $72.3 \%)$ compared to colposcopy and colposcopy had a better Sensitivity $(90.24 \%$ versus $19.5 \%)$ compared to Pap smear (Table 11). ${ }^{17}$

Table 11: Correlation between pap smear, colposcopy and histopathology.

\begin{tabular}{|c|c|c|c|c|c|}
\hline Study & Sensitivity (\%) & Specificity (\%) & $\begin{array}{l}\text { Positive predictive } \\
\text { value }(\%)\end{array}$ & $\begin{array}{l}\text { Negative predictive } \\
\text { value }(\%)\end{array}$ & p value \\
\hline \multicolumn{6}{|c|}{ Correlation of Pap smear with colposcopy } \\
\hline Ashmita D et al & $22.5 \%$ & $100 \%$ & $100 \%$ & $27.9 \%$ & 0.097 \\
\hline Present study & $78 \%$ & $92 \%$ & $52 \%$ & $97 \%$ & $<0.0001$ \\
\hline \multicolumn{6}{|c|}{ Correlation of Pap smear with histopathology } \\
\hline Ashmita D et al & $19.5 \%$ & $83.3 \%$ & $80 \%$ & $23.26 \%$ & 0.329 \\
\hline Present study & $82.3 \%$ & $97.1 \%$ & $82.3 \%$ & $97.1 \%$ & $<0.0001$ \\
\hline \multicolumn{6}{|c|}{ Correlation of colposcopy with histopathology } \\
\hline Ashmita D et al & $90.2 \%$ & $72.7 \%$ & $92.5 \%$ & $66.67 \%$ & $<0.001$ \\
\hline Present study & $67 \%$ & $100 \%$ & $100 \%$ & $95 \%$ & $<0.0001$ \\
\hline
\end{tabular}

\section{CONCLUSION}

Colposcopic indices like the Reid score performed well in terms of both sensitivity and specificity and correlates well with histological results in case of cervical disease and evaluation of its severity while swede score also had fairly good sensitivity but low specificity for CIN1+ lesions which eventually improved as the severity of lesions increase to CIN2+ or more. All women of study population with swede score of 8 or more was found to have CIN3 or ICC. So, study recommend doing colposcopy and treating lesion then and there if swede score is 8 or higher. Thus, it is concluded that both scores performed well in this hospital-based study on a selected 
population and both the scores can be flexibly used with additional advantage of Swede score for incorporating lesion size. The lower threshold with high sensitivity can be used for screening while the higher threshold with high specificity can be used to screen and treat lesion, making easier for health workers in low resource settings to assess the feasibility of treatment modalities. The study being done on large population eliminates verification bias to an extent but despite the substantial compliance with histologic results, if inter-observer variability is taken into consideration, more research and large studies are needed to assess and improve the diagnostic accuracy of colposcopy.

Funding: No funding sources Conflict of interest: None declared

Ethical approval: The study was approved by the Institutional Ethics Committee

\section{REFERENCES}

1. Bray F, Ferlay J, Soerjomataram I, Siegel RL, Torre LA, Jemal CA. Up to date, Global cancer statistics 2018: Globocan estimates of incidence and mortality worldwide for 36 cancers in 185 countries. Cancer J Clin. 2018;68(6):394.

2. Coppleson M, PixleyJM, Reid B. Colposcopy: a scientific and practical approach to the cervix in health and disease. Springfield, IL: CharlesC. Thomas; 1978.

3. Ramadevi E, Mamata N, Madhavi GB, Sudha RV, Padmalatha R, Shamili G. A study of correlation between cytologyand histopathology with colposcopicfindings. Int J Int Med Sci. 2017;4(4):47783.

4. Vaidya, Olaniyan OB. Validity of colposcopy in the diagnosis of early cervical neoplasia a review. Af J Reprod Health. 2002;6:59-69.

5. Shalini R, Amitha S, Neera MA. How alarming is post coital bleeding-a cytologic, colposcopic and histological evaluation. Gynaecol Obstet Invest. 1998;45(3):205-8.

6. Ale OV, Omonua KI, Onafowokan O. Correlation between colposcopic impression and histologic diagnosis of premalignant lesions of the cervix. Postgraduate Med J Ghana. 2019;8:2.

7. Slattery ML, Robison LM, Schuman KL. Cigarette smoking and exposure to passive smoke are risk factors for cervical cancer. JAMA. 1989;261(11):1593-8.

8. Brinton LA, Reeves WC, Brenes MM, Herrero R, De Brilton RC, Gaitan E, et al. Parity as a risk factor for cervical cancer. Am J Epidemiol. 1989;130(3):486-96.

9. Chhabra Y, Behera BG, Khalkho J. Cytomorphological study of PAP smears for precancerous and cancerous lesions. J Cytol. 2003;20:64-7.

10. Bukhari MH, Saba K, Qamar S, Majeed MM, Niazi S, Naeem S. Clinicopathological importance of Papanicolaou smears for the diagnosis of premalignant and malignant lesions of the cervix. J Cytol Indian Acad Cytol. 2012;29(1):20-5.

11. Kärrberg C, Ryd W, Strander B, Brännström M, Rådberg T. Histological diagnosis and evaluation of the swede score colposcopic system in a large cohort of pregnant women with atypical cervical cytology or cervical malignancy signs. Acta Obstet Gynecol Scand. 2012;91:952-8.

12. Durdi GS, Sherigar BY, Dalal AM, Desai BR, Malur PR. Correlation of colposcopy using reid colposcopic index with histopathology- a prospective study. J Turk Ger Gynecol Assoc. 2009;10:205-7.

13. Ranga R, Rai S, Kumari A, Mathur S, Kriplani A, Mahey R, et al. A comparison of the strength of association of Reid colposcopic index and Swede Score with cervical histology. J Lower Genital Tract Dis. 2017;21(1):55-8.

14. Penumalli S, Kasthuri TB. Evaluation of colposcopy using swede score in screening of cervical cancer. J Evol Med Dent Sci. 2017;6(94):6868-71.

15. Abdel-Hadi M, Khalaf A, Aboulkassem H, Naeem N, Baqy MA, Sallam H. Cervical intraepithelial lesions in females attending Women's Health Clinics in Alexandria, Egypt. Cyto J. 2015;12:13.

16. Basu P, Mittal S, Bhaumik S, Mandal SS, Samaddar A, Ray C, et al. Prevalence of high-risk human papillomavirus and cervical intraepithelial neoplasias in a previously unscreened population-a pooled analysis from three studies. Int J Cancer. 2013;132(7):1693-9.

17. Ashmita D, Shakuntala PN, Rao SR, Sharma SK, Geethanjali S. Comparison and correlation of pap smear, coploscopy and histopathology in symptomatic women and suspicious looking cervix in a tertiary hospital care centre. Int J Health Sci Res. 2013;3(5):509.

18. Bowring J, Strander B, Young M, Evans H, Walker P. The swede score: Evaluation of a scoring system designed to improve the predictive value of colposcopy. J Low Genit Tract Dis. 2010;14:301-5.

19. Strander B, Ellström-Andersson A, Franzén S, Milsom I, Rådberg T. The performance of a new scoring system for colposcopy in detecting high-grade dysplasia in the uterine cervix. Acta Obstet Gynecol Scand. 2005;84:1013-7.

20. Singla S, Mathur S, Kriplani A, Agarwal N, Garg P, Bhatla N, et al. Single visit approach for management of cervical intraepithelial neoplasia by visual inspection and amp; loop electrosurgical excision procedure. Indian J Med Res. 2012;135:614-20.

21. Kushwah S, Kushwah B. Correlation of two colposcopic indices for predicting premalignant lesions of cervix. J Mid-life Health. 2017;8:118-23.

22. Kierkegaard O, Byralsen C, Hansen KC, Frandsen KH, Frydenberg M. Association between colposcopic findings and histology in cervical lesions: The significance of the size of the lesion. Gynecol Oncol. 1995;57:66-71.

Cite this article as: Karya U, Zehra A, Rani A. Evaluation of Swede score and Reid score to improve the predictive value of colposcopy and its correlation with histology. Int J Reprod Contracept Obstet Gynecol 2020;9:2059-67. 